\title{
Hydrogen $\left(\mathrm{H}_{2}\right)$ uptake and physisorption in clay-rich formations
}

RACHID TCHALALA ${ }^{1}$, VALERIE MAGNIN ${ }^{1}$, NATHANIEL FINDLING $^{2}$, DENYS GREKOV ${ }^{3}$ AND LAURENT TRUCHE ${ }^{4}$

${ }^{1}$ ISTerre, University Grenoble Alpes

${ }^{2}$ ISTerre-UGA

${ }^{3}$ IMT Atlantique, Département Systèmes Energétiques et

Environnement

${ }^{4}$ University Grenoble Alpes

Presenting Author: rachid.tchalala@univ-grenoble-alpes.fr

Hydrogen $\left(\mathrm{H}_{2}\right)$ mobility in the Earth's crust is a critical matter both for deep nuclear waste disposal, where corrosion of steel canisters can produce copious amounts of hydrogen and largescale underground hydrogen storage that might act as a future key component for electrical power grid management. Beyond its reactivity at low temperature with oxidized species in solution or in the host rock (e.g., sulfates, carbonates, and oxides) in the presence of suitable catalysts or microbial activity [1], $\mathrm{H}_{2}$ may all be entrapped at the surface of minerals by physisorption mechanism - as it is the case for other gases such as methane or $\mathrm{CO}_{2}$ [2-3]. These water-rock-gas interactions could lead to a loss of $\mathrm{H}_{2}$, corrosion of the metallic infrastructures, or compromise the geological formation's integrity by mineralogical transformations. Besides, natural hydrogen sources could potentially represent a new primary energy resource.

Here, we measure $\mathrm{H}_{2}$ sorption isotherms on natural claystone samples at low (up to 1 bar) and high (up to 100 bars) pressures and from $77 \mathrm{~K}$ to ambient temperature. We report very recent advances in using raw and purified samples of CallovoOxfordian and Boom clay as a medium for hydrogen sorption and retention to uncover their corresponding unique structural properties - gas adsorption relationships. Sorbent characterization using PXRD, TGA, and $\mathrm{N}_{2}$ adsorption were conducted to reveal the structure and stability of the sorbents. Diffraction data reveal significant mineralogical differences between different samples. TGA analysis were investigated to establish the thermal stability of the sorbents under various temperatures. Results from the $\mathrm{N}_{2}$ sorption isotherm indicate that before and after purification, the surface area increases significantly, owing to the removal of minerals phases with low or negligible SSA. Volumetric measurements used to determine hydrogen uptake confirmed the trend observed in nitrogen isotherms: the amount of hydrogen adsorbed increases proportionally with the apparent BET surface area, indicating that the hydrogen adsorption process is similar in those materials.

\section{References:}

[1] L Truche, et al. (2013). App. Geochem. 35, 279-288.

[2] L Truche, et al. (2018). EPSL 493, 186-197.

[3] J. S. Edge, (2014). J. Phys. Chem.C, 118,25740-7. 